\title{
Adenocarcinoma with Cartilaginous and Osseous Metaplasia
}

National Cancer Institute

\section{Source}

National Cancer Institute. Adenocarcinoma with Cartilaginous and Osseous Metaplasia. NCl Thesaurus. Code C7683.

An invasive adenocarcinoma characterized by focal or extensive cartilage and/or bone formation. 